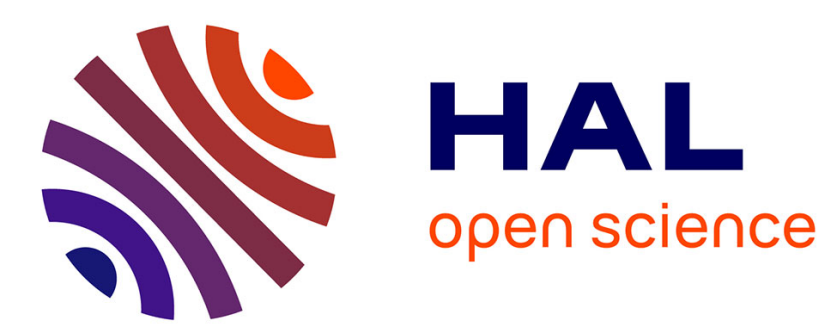

\title{
Tuning the organization of the interlayer organic moiety in a hybrid layered perovskite
}

Yanhui Wang, Cédric Leuvrey, Emilie Delahaye, Fabrice Leroux, Pierre Rabu, Christine Taviot-Gueho, Guillaume Rogez

\section{- To cite this version:}

Yanhui Wang, Cédric Leuvrey, Emilie Delahaye, Fabrice Leroux, Pierre Rabu, et al.. Tuning the organization of the interlayer organic moiety in a hybrid layered perovskite. Journal of Solid State Chemistry, 2019, 269, pp.532-539. 10.1016/j.jssc.2018.10.034 . hal-02194206

\section{HAL Id: hal-02194206 https://hal.science/hal-02194206}

Submitted on 17 Jan 2022

HAL is a multi-disciplinary open access archive for the deposit and dissemination of scientific research documents, whether they are published or not. The documents may come from teaching and research institutions in France or abroad, or from public or private research centers.
L'archive ouverte pluridisciplinaire HAL, est destinée au dépôt et à la diffusion de documents scientifiques de niveau recherche, publiés ou non, émanant des établissements d'enseignement et de recherche français ou étrangers, des laboratoires publics ou privés. 


\title{
Tuning the organization of the interlayer organic moiety in a hybrid layered perovskite
}

\author{
Yanhui Wang, ${ }^{a}$ Cédric Leuvrey, ${ }^{a}$ Emilie Delahaye, ${ }^{a}$ Fabrice Leroux, ${ }^{b}$ Pierre Rabu, ${ }^{a}$ Christine \\ Taviot-Guého, ${ }^{b^{*}}$ Guillaume Rogez ${ }^{a^{*}}$ \\ a) IPCMS, UMR Unistra-CNRS 7504, 23 rue du Loess, BP 43, 67034 Strasbourg cedex 2, \\ France \\ b) Institut de Chimie de Clermont-Ferrand, Equipe Matériaux Inorganiques, CNRS UMR \\ 6296, UFR Sciences et Technologies, 24 avenue des Landais, BP 80026, 63171 Aubière \\ cedex, France
}

christine.taviot-gueho@uca.fr

rogez@unistra.fr

Dedicated to Prof. S. H. Choy on the occasion of his retirement.

\begin{abstract}
The insertion of phenylbutylamine into a layered perovskite of formula $\mathrm{H}_{2} \mathrm{Bi}_{0.1} \mathrm{Sr}_{0.85} \mathrm{Ta}_{2} \mathrm{O}_{7}$ (HST) has been investigated as a function of the synthesis conditions. For short reactions times $(1.5 \mathrm{~h})$, achieved using microwave assisted reactions, a short interlayer distance $(2.2$ $\mathrm{nm}$ ) is obtained (PBA1-HST) whereas for long reaction times (18 h) achieved using classical solvothermal reaction, a much larger interlayer distance is obtained (3.0 nm) (PBA3-HST). The compounds are well crystallized despite a more pronounced disorder of the organic moiety for PBA1-HST, evidenced by IR spectroscopy. The organic loading is very similar for both phases, and no difference in the ${ }^{13} \mathrm{C} C P / M A S$ solid state NMR spectra could be evidenced. 1D electron density profiles established from XRD patterns allow to precise the organization of the molecules within the interlayer space. More subtle variations of the reaction parameters tend to show that there is a gradual evolution from the kinetic product, PBA1-HST, to the thermodynamic one, PBA3-HST, but it has not been possible to isolate a monophasic intermediate phase. Yet a compound with an intermediate interlayer distance could be isolated as a pure phase, using a prefunctionalized precursor as starting material (PBA2-HST, $2.7 \mathrm{~nm}$ ). It was finally shown that it is possible to realize a mutual conversion of PBA2-HST and PBA3-HST by post-synthesis solvent treatment.

This work completes the emerging studies on microwave-assisted functionalization of layered oxides and paves the way to a fine tailoring of hybrid materials with specific structures and properties.
\end{abstract}

\section{Keywords}

Hybrid materials; Layered perovskites; Aurivillius phase; Microwave; Phenylbutylamine; 1D electron density profile; Interdigitation 


\section{Introduction}

Besides graphene and transition metal dichalcogenides (TMDs), other 2D nanosheet-based materials have attracted a lot of attention in the last years.[1-6] Among them one may quote oxide and hydroxide nanosheets, with applications in the field of energy (fuel cells,

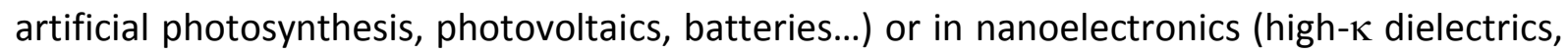
ferroelectrics, multiferroics...).[3,7-9] One important characteristic of these oxide and hydroxide nanosheets is that they are obtained from bulk layered 2D materials which can be functionalized by various kind of reactions, insertion, insertion grafting or post-synthesis modification reactions.[10-12] This field, very recently reviewed,[9] has experienced a renewed interest in the past few years, thanks to the development of microwave-assisted reactions.[13-17] Yet, despite the interest of this approach and notably the considerable gain in reaction time, it appears that the possible differences in the obtained products using microwave-assisted reactions or more classical ones have not been really explored. This could be of utmost importance since it has been shown for instance for the functionalization of layered double hydroxides that interesting and complex mechanisms could arise below apparently simple reaction processes. [18-20]

Based on our experience on the microwave-assisted functionalization and post-synthesis modification of an Aurivillius phase of formula $\mathrm{Bi}_{2} \mathrm{SrTa}_{2} \mathrm{O}_{9}$ (BST), we describe in this article one example of the strong influence of the reaction conditions on the obtained product of the functionalization of HST with a particular amine, phenylbutylamine (PBA) (scheme 1).

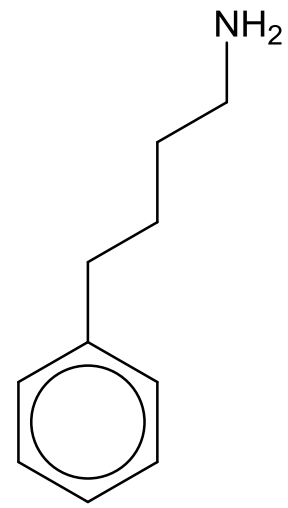

Scheme 1. Phenylbutylamine (PBA).

This amine is characterized by a flexible alkyl chain bearing the amino group, and a rigid moiety at the other side of the molecule. We investigate here the reaction between this amine and a protonated Aurivillius phase of formula $\mathrm{H}_{2} \mathrm{Bi}_{0.1} \mathrm{Sr}_{0.85} \mathrm{Ta}_{2} \mathrm{O}_{7}$ (HST) as a function of the synthesis conditions: using short reactions times by means of microwave assisted reactions and longer reaction times using classical solvothermal reaction. The compounds are characterized using ancillary techniques (XRD, IR, ${ }^{13} \mathrm{C} C P / M A S$ solid state NMR spectroscopy). 1D electron density profiles extracted from XRD patterns allow to precise the organization of the molecules within the interlayer space. Finally, using a slightly different starting compound (HST prefunctionalized by ethyl amine), a compound with another molecular organization could be isolated as a pure phase. The possibility to realize a mutual conversion between these phases by post-synthesis solvent treatment was finally explored. 


\section{Experimental Section}

\section{Syntheses}

Microwave syntheses were performed with a microwave synthesis reactor Monowave 300 (Anton Paar) (non-acidic conditions) and with a microwave synthesis reactor MultiwaveGO (Anton Paar) for the synthesis of HST (acidic conditions).

$\mathrm{Bi}_{2} \mathrm{SrTa}_{2} \mathrm{O}_{9}$ (BST), $\mathrm{H}_{2} \mathrm{Bi}_{0.1} \mathrm{Sr}_{0.85} \mathrm{Ta}_{2} \mathrm{O}_{7}$ (HST) and $\left(\mathrm{CH}_{3} \mathrm{CH}_{2} \mathrm{NH}_{3}\right)_{0.8} \mathrm{H}_{1.2} \mathrm{Bi}_{0.1} \mathrm{Sr}_{0.85} \mathrm{Ta}_{2} \mathrm{O}_{7} \cdot 3 \mathrm{H}_{2} \mathrm{O}\left(\mathrm{C}_{2} \mathrm{~N}-\right.$ HST) were synthesized according to published procedures.[13]

$\left(\mathrm{C}_{6} \mathrm{H}_{5}\left(\mathrm{CH}_{2}\right)_{4} \mathrm{NH}_{3}\right)_{0.5} \mathrm{H}_{1.5} \mathrm{Bi}_{0.1} \mathrm{Sr}_{0.85} \mathrm{Ta}_{2} \mathrm{O}_{7} \cdot \mathbf{1 . 4 H}_{2} \mathrm{O}$ (PBA1-HST): $100 \mathrm{mg}$ (0.17 mmol) of HST were dispersed in a solution of $20 \mathrm{mmol}$ of PBA ( $3 \mathrm{~mL}$ ) in a mixture of $5 \mathrm{~mL}$ of THF and $1 \mathrm{~mL}$ of water. The mixture was placed in a $30 \mathrm{~mL}$ vial and heated by microwave irradiation at $130^{\circ} \mathrm{C}$ during $1.5 \mathrm{~h}$ (maximum incident power: $70 \mathrm{~W}$ ). In these conditions, the mean incident power was about $10 \mathrm{~W}$, and the autogenous pressure was about 6 bars. The obtained white powder was collected after three centrifugations (14000 rpm (18400 g), $5 \mathrm{~min}$ each) (the supernatant was replaced after each centrifugation by distilled water (twice) and ethanol (last) in order to wash the product) and air-dried.

$\left(\mathrm{C}_{6} \mathrm{H}_{5}\left(\mathrm{CH}_{2}\right)_{4} \mathrm{NH}_{3}\right)_{0.6} \mathrm{H}_{1.4} \mathrm{Bi}_{0.1} \mathrm{Sr}_{0.85} \mathrm{Ta}_{2} \mathrm{O}_{7} \cdot \mathbf{1 . 6 H}_{2} \mathrm{O}$ (PBA2-HST): the same procedure as above was used, using $100 \mathrm{mg}(0.15 \mathrm{mmol})$ of $\mathrm{C}_{2} \mathrm{~N}$-HST instead of HST.

$\left(\mathrm{C}_{6} \mathrm{H}_{5}\left(\mathrm{CH}_{2}\right)_{4} \mathrm{NH}_{3}\right)_{0.5} \mathrm{H}_{1.5} \mathrm{Bi}_{0.1} \mathrm{Sr}_{0.85} \mathrm{Ta}_{2} \mathrm{O}_{7} \cdot 1.0 \mathrm{H}_{2} \mathrm{O}$ (PBA3-HST): $100 \mathrm{mg}$ (0.17 mmol) of HST were dispersed in a solution of $20 \mathrm{mmol}$ of PBA $(3 \mathrm{~mL})$ in a mixture of $5 \mathrm{~mL}$ of THF and $1 \mathrm{~mL}$ of water. The mixture was placed in a sealed Teflon-lined autoclave (volume $50 \mathrm{~mL}$ ) and was heated in oven at $130^{\circ} \mathrm{C}$ during $18 \mathrm{~h}$. The obtained white powder was collected after three centrifugations (14000 rpm (18400 g), 5 min each) (the supernatant was replaced after each centrifugation by distilled water (twice) and ethanol (last) in order to wash the product) and air-dried.

The results of elemental analyses and TGA and the proposed formulae are given in Table 1.

Caution: even though no problem was encountered in the course of this research, special care must be taken while working with sealed glass containers. Containers must be carefully checked for any defect, and replaced if necessary to avoid possible explosion. Amines and concentrated hydrochloric acid are corrosive and irritating.

\section{Characterization procedures}

Elemental analyses for $\mathrm{C}, \mathrm{H}$ and $\mathrm{N}$ were carried out at the Service Commun d'Analyses of the University of Strasbourg. The SEM images were obtained with a JEOL 6700F microscope equipped with a field emission gun, operating at $3 \mathrm{kV}$ in the SEI mode. FT-IR spectra were collected in ATR mode on a Spectrumll spectrometer (Perkin-Elmer). TGA-TDA experiments were performed using a TA instrument SDT Q600 (heating rates of $5^{\circ} \mathrm{C} \cdot \mathrm{min}^{-1}$ under air stream, using alumina crucibles). NMR spectra in solution were recorded using a Bruker AVANCE $300(300 \mathrm{MHz})$ spectrometer. Solid state NMR ${ }^{13} \mathrm{C}(I=1 / 2)$ experiments were performed with a 300 Bruker spectrometer at $75.47 \mathrm{MHz}$, using magic angle spinning (MAS) condition at $10 \mathrm{kHz}$ and a $4 \mathrm{~mm}$ diameter size zirconia rotor. ${ }^{13} \mathrm{C}$ spectra obtained by proton enhanced cross-polarization method (CP) were referenced to the carbonyl of the glycine 
calibrated at 176.03 ppm. Recycling and Hartman-Hahn contact times were $5 \mathrm{~s}$ and $1250 \mu \mathrm{s}$, respectively. Spinal $64{ }^{1} \mathrm{H}$ phase-decoupling was applied during ${ }^{13} \mathrm{C}$ channel acquisition.

\section{X-ray diffraction analysis}

The powder XRD patterns were collected in Bragg Brentano geometry with a Bruker D8 diffractometer (CuK $\alpha 1=0.1540598 \mathrm{~nm}$ ) equipped with a LynxEye detector discriminating in energy. For Le Bail refinement, a step size of $0.02^{\circ}(2 \theta)$ and a counting time of 14 s per step were used.

The Le Bail method consisting in the full pattern decomposition of the XRD pattern of the powdered sample was used to determine the cell parameters assuming the $14 / \mathrm{mmm}$ space group, typical for BST and HST materials, $[21,22]$ and to extract the intensities of diffraction peaks. The refinement was carried out using Fullprof suite program.[23] The pseudo-Voigt profile function of Thompson, Cox and Hastings was selected to analyze peak profiles.[24] The instrumental contribution to peak broadening was estimated by measuring the standard corundum reference sample leading to the following Caglioti half-width parameters: $U=$ $0.0111 \mathrm{~V}=-0.0041$ and $\mathrm{W}=0.0016$.

It should be noted that two phases of same composition but with different profile parameters had to be considered to reach a good fit and this is due to the presence of two different particle sizes as evidenced by SEM analysis (Fig. S3 shows a representative SEM image of the compounds obtained in this study).

The one-dimensional electron density distributions along the c-stacking axis were calculated for PBA3-HST and PBA2-HST samples from the intensity of the $00 /$ diffraction lines according to the following equation:

$$
\rho(z)=\sum_{l=0}^{\infty} \mathrm{F}_{00 l} \cos \left(\frac{2 \pi l z}{c}\right)
$$

where $c$ is the unit cell parameter, $z$ is the fractional coordinate along the $c$-stacking axis, and $F_{001}$ are the structures factors.[25] Thirteen isolated $00 /$ diffraction lines were used for calculating the 1D plots. The signs of the structure factors were obtained from the scattering contributions of the perovskite layers assuming a relatively small contribution of the intercalated molecules. For comparison, the 1D electron density profile along the z-direction for BST was simulated (Fig. S4); it was calculated from the crystal structure data taken from Crystallography Open Datatabase (entry 1521701).

The difference Fourier map for PBA3-HST was calculated using GFourier program by employing the observed structure factors $F_{\text {obs }}$ extracted from the Le Bail whole powder diffraction pattern decomposition and plotted in the form of contour plots summed from 0 to 1 along the $a$-axis. The known part of the structure i.e. the perovskite layer was entered and the corresponding calculated structure factors were substracted from the $F_{\text {obs }}$ thus emphasizing the electron density in the interlayer space.

A simple structural model was proposed for PBA3-HST obtained by treating the intercalated PBA anion as a quasi rigid body and comparing the resulting calculated Fourier map with the above experimental difference Fourier map. The molecular structure of phenylbutylamine was built using ChemBio 3D Utra 13.0 Suite program; energy minimization and geometric optimization were applied using the MM2 forced field implemented in the program. The nitrogen atom of the amine group was chosen to express the rigid body in orthonormal coordinates; it was positioned on $x_{c}=0.0, y_{c}=0.0, z_{c}=0.10568$ corresponding to 4 e position 
in $14 / \mathrm{mmm}$ space group with a site occupancy of $1 / 4$. This absolute position and the Euler angles theta $=65^{\circ}$, phi $=70^{\circ}$, chi $=175^{\circ}$ describe the molecular body orientation. The profile parameters and unit cells used were those determined from Le Bail profile fitting.

\section{Results and discussion}

\subsection{Synthesis and structural analysis}

The syntheses of the three PBA-HST hybrids were performed using a large excess $(c a . \times 100)$ of PBA with respect to $\mathbf{H S T}$ or $\mathbf{C}_{2} \mathbf{N}-\mathbf{H S T}$, in a THF/ $\mathrm{H}_{2} \mathrm{O}$ mixture (5:1 v:v). The PBA1-HST and PBA2-HST phases were obtained by reaction between PBA and HST and $\mathbf{C}_{2} \mathbf{N}-\mathbf{H S T}$ respectively using microwave irradiation $\left(130^{\circ} \mathrm{C}, 1.5 \mathrm{~h}\right)$ following the method established previously for aliphatic amines.[13,14] The PBA3-HST phase was obtained using classical solvothermal heating in a Teflon-lined autoclave under autogenous pressure $\left(130^{\circ} \mathrm{C}, 18 \mathrm{~h}\right)$ (see Experimental).

Fig. 1 shows the powder XRD patterns (raw data) of HST, $\mathbf{C}_{\mathbf{2}} \mathbf{N}-\mathbf{H S T}$ and the three reaction products. The layered structure is evidenced by the series of intense $(00 /)$ reflections at low angles. After reactions the interlayer distances increase from that of HST $(0.98 \mathrm{~nm})$ to 2.20 $\mathrm{nm}$ for PBA1-HST and to $3.00 \mathrm{~nm}$ for PBA3-HST. For PBA2-HST, the interlayer distance increases from that of $\mathbf{C}_{2} \mathbf{N}-H S T(1.57 \mathrm{~nm})$ to $2.67 \mathrm{~nm}$. The $(0 O /)$ reflection lines of the starting products are not visible in the diagrams of the reaction products. In contrast, the characteristic out-of-plane reflections assigned to (100) and (110) in the XRD pattern of HST, are observed at the same positions $\left(22.68^{\circ}(0.392 \mathrm{~nm})\right.$ and $32.59^{\circ}(0.274 \mathrm{~nm})$ respectively) for the three phases. Therefore, after the intercalation reactions, the structures of the inorganic perovskite-like slabs are retained. In Fig. 2 are reported the Le Bail whole-powderdiffraction-pattern profile fittings for PBA2-HST and PBA3-HST samples. As can be seen, satisfactory refinements were obtained by considering a tetragonal cell with the space group $14 / \mathrm{mmm}$. On the other hand, in the case of PBA1-HST sample, we were not able to do similar refinement due to an anisotropic broadening of X-ray diffraction peaks, thus the interlayer distance was estimated from the position of the 001 diffraction lines. After reactions, the interlayer distances increase from that of HST $(0.98 \mathrm{~nm})$ to c.a. $2.20 \mathrm{~nm}$ for PBA1-HST and to $2.98 \mathrm{~nm}$ for PBA3-HST. For PBA2-HST, the interlayer distance increases from that of $\mathbf{C}_{\mathbf{2}} \mathbf{N}$-HST $(1.57 \mathrm{~nm})$ to $2.67 \mathrm{~nm}$. By subtracting the perovskite layer thickness i.e. $0.765 \mathrm{~nm}$ from these interlayer distances, one can estimate the distance available for PBA molecule in the interlayer space: $2.215 \mathrm{~nm}$ for PBA3-HST, $1.905 \mathrm{~nm}$ for PBA2-HST and $1.420 \mathrm{~nm}$ for PBA1HST. Comparing these values to the estimated length of the guest species c.a. $0.85 \mathrm{~nm}$ suggests a bilayer arrangement of PBA, probably interdigitated in the case of PBA1-HST, with the amino groups nearby the perovskite layers.

The observed interlayer distances are in total agreement with a bilayer insertion of the phenylbutylamine, with different interdigitation rates and/or different angles between the molecule and the inorganic layer. 


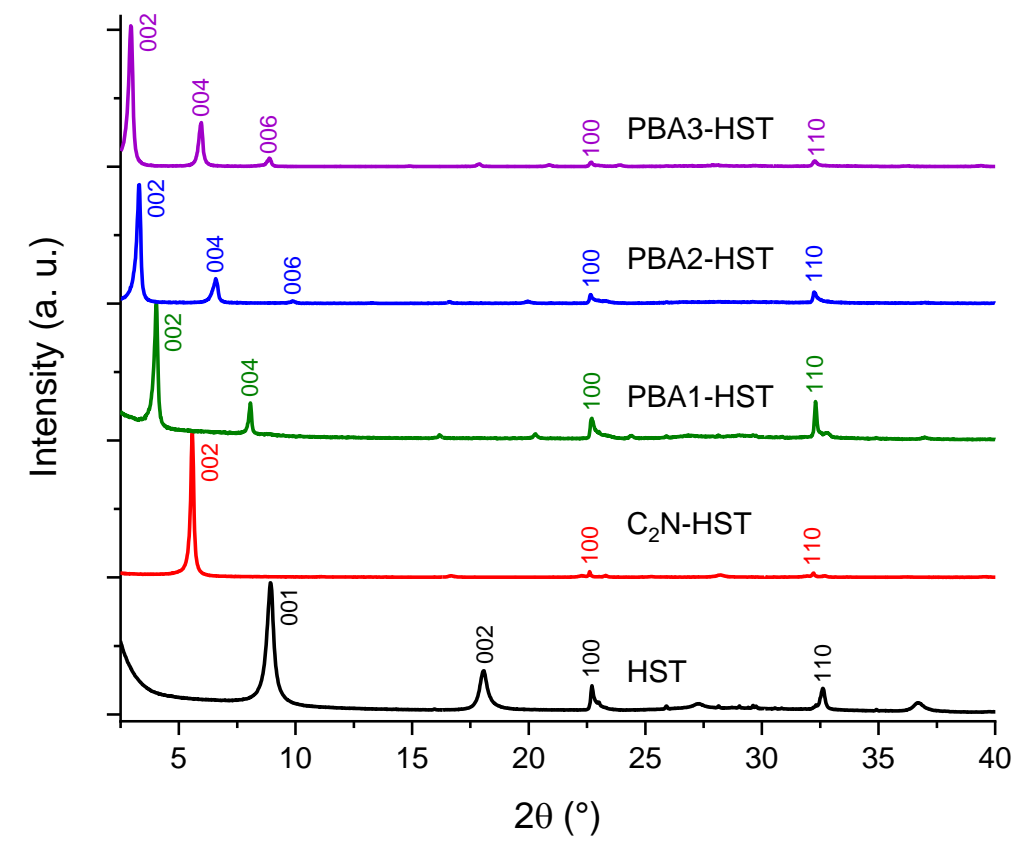

Figure 1. PXRD patterns of HST (black), $\boldsymbol{C}_{2}$ N-HST (red), PBA1-HST (green), PBA2-HST (blue) and PBA3-HST (purple).

The elemental analyses and thermogravimetric analyses show that there is no obvious difference in the insertion rates and in the water content between the three phases (Tab. 1 and Fig. S1).

Table 1. Mass losses ascribed to the removal of water and of organic phase, elemental micro-analyses $(C, H, N)$ and consistent proposed formulae.

\begin{tabular}{|c|c|c|c|c|c|c|c|}
\hline Compound & Formula & $\begin{array}{c}\text { Mass losses } \\
\text { (water+organic } \\
\text { ) } \\
\text { found } \\
\text { (calcd) } \\
\text { (\%) }\end{array}$ & $\begin{array}{l}\text { Mass losses } \\
\text { (organic) } \\
\text { found } \\
\text { (calcd) } \\
\text { (\%) }\end{array}$ & $\begin{array}{l}\text { Mass losses } \\
\text { (water) } \\
\text { Found } \\
\text { (calcd) } \\
\text { (\%) }\end{array}$ & $\begin{array}{l}\text { C content } \\
\text { Found } \\
\text { (calcd) } \\
(\%)\end{array}$ & $\begin{array}{l}\text { H content } \\
\text { Found } \\
\text { (calcd) } \\
(\%)\end{array}$ & $\begin{array}{l}\text { N content } \\
\text { Found } \\
\text { (calcd) } \\
\text { (\%) }\end{array}$ \\
\hline PBA1-HST & $\left(\mathrm{C}_{10} \mathrm{NH}_{16}\right)_{0.5} \mathrm{H}_{1.5} \mathrm{Bi}_{0.1} \mathrm{Sr}_{0.85} \mathrm{Ta}_{2} \mathrm{O}_{7} \cdot 1.4 \mathrm{H}_{2} \mathrm{O}$ & $15.1(14.9)$ & $11.1(11.1)$ & $4.0(3.8)$ & $11.06(9.0)$ & $1.97(1.8)$ & $1.28(1.0)$ \\
\hline PBA2-HST & $\left(\mathrm{C}_{10} \mathrm{NH}_{16}\right)_{0.6} \mathrm{H}_{1.4} \mathrm{Bi}_{0.1} \mathrm{Sr}_{0.85} \mathrm{Ta}_{2} \mathrm{O}_{7} \cdot 1.6 \mathrm{H}_{2} \mathrm{O}$ & $16.6(17.2)$ & $12.6(13.0)$ & $4.0(4.2)$ & $13.55(10.4)$ & $2.24(2.4)$ & $1.52(1.2)$ \\
\hline PBA3-HST & $\left(\mathrm{C}_{10} \mathrm{NH}_{16}\right)_{0.5} \mathrm{H}_{1.5} \mathrm{Bi}_{0.1} \mathrm{Sr}_{0.85} \mathrm{Ta}_{2} \mathrm{O}_{7} \cdot 1.0 \mathrm{H}_{2} \mathrm{O}$ & $13.3(13.9)$ & $10.3(11.2)$ & $3.0(2.7)$ & $10.01(9.0)$ & $1.74(1.7)$ & $1.25(1.0)$ \\
\hline
\end{tabular}

The three different phases present identical thermal behaviours (Fig. S1). The first mass losses (4\%, 4\% and 3\% for PBA1-HST, PBA2-HST and PBA3-HST, respectively) occur before $125^{\circ} \mathrm{C}$ and are ascribed to the removal of water. The TGA curves show very obvious mass losses (11.1\%, 12.6\% and 10.3\% for PBA1-HST, PBA2-HST and PBA3-HST, respectively) between $125{ }^{\circ} \mathrm{C}$ and $500{ }^{\circ} \mathrm{C}$, associated to exothermic events. This second mass loss is thus attributed to the removal of PBA. The mass losses ( $\mathrm{ca} .3 \%$ ) between $600^{\circ} \mathrm{C}$ and $700^{\circ} \mathrm{C}$ are ascribed to the loss of protons in the form of water. By analogy with what has been described on $\mathrm{H}_{2} \mathrm{SrTa}_{2} \mathrm{O}_{7},[26,27]$ the obtained phase is a three-dimensional perovskite of formula $\mathrm{Bi}_{0.1} \mathrm{Sr}_{0.85} \mathrm{Ta}_{2} \mathrm{O}_{6}$. Finally, the mass losses around $900{ }^{\circ} \mathrm{C}(1.6 \%, 1.2 \%$ and $1.0 \%$ for PBA1-HST, PBA2-HST and PBA3-HST, respectively), associated with an exothermic event, are proposed to be due to partial $\mathrm{Bi}$ removal and formation of the tungsten bronze phase $\alpha$ $\mathrm{Bi}_{0.1} \mathrm{Sr}_{0.85} \mathrm{Ta}_{2} \mathrm{O}_{6}$. XRD pattern of the intermediate and final phases, as well as phase matching 
for the final phase are presented in Fig. S2. According to the above analyses, the formulae of the three phases PBA1-HST, PBA2-HST and PBA3-HST can be estimated as follows: $\left(\mathrm{C}_{6} \mathrm{H}_{5}\left(\mathrm{CH}_{2}\right)_{4} \mathrm{NH}_{3}\right)_{0.5} \mathrm{H}_{1.5} \mathrm{Bi}_{0.1} \mathrm{Sr}_{0.85} \mathrm{Ta}_{2} \mathrm{O}_{7} \cdot 1.4 \quad \mathrm{H}_{2} \mathrm{O}, \quad\left(\mathrm{C}_{6} \mathrm{H}_{5}\left(\mathrm{CH}_{2}\right)_{4} \mathrm{NH}_{3}\right)_{0.6} \mathrm{H}_{1.4} \mathrm{Bi}_{0.1} \mathrm{Sr}_{0.85} \mathrm{Ta}_{2} \mathrm{O}_{7} \cdot 1.6 \mathrm{H}_{2} \mathrm{O}$ and $\left(\mathrm{C}_{6} \mathrm{H}_{5}\left(\mathrm{CH}_{2}\right)_{4} \mathrm{NH}_{3}\right)_{0.5} \mathrm{H}_{1.5} \mathrm{Bi}_{0.1} \mathrm{Sr}_{0.85} \mathrm{Ta}_{2} \mathrm{O}_{7} \cdot 1.0 \quad \mathrm{H}_{2} \mathrm{O}$, respectively. The organic molecules content is thus essentially similar for the three phases, making it very unlikely to be the principle reason for the difference in interlayer distance.

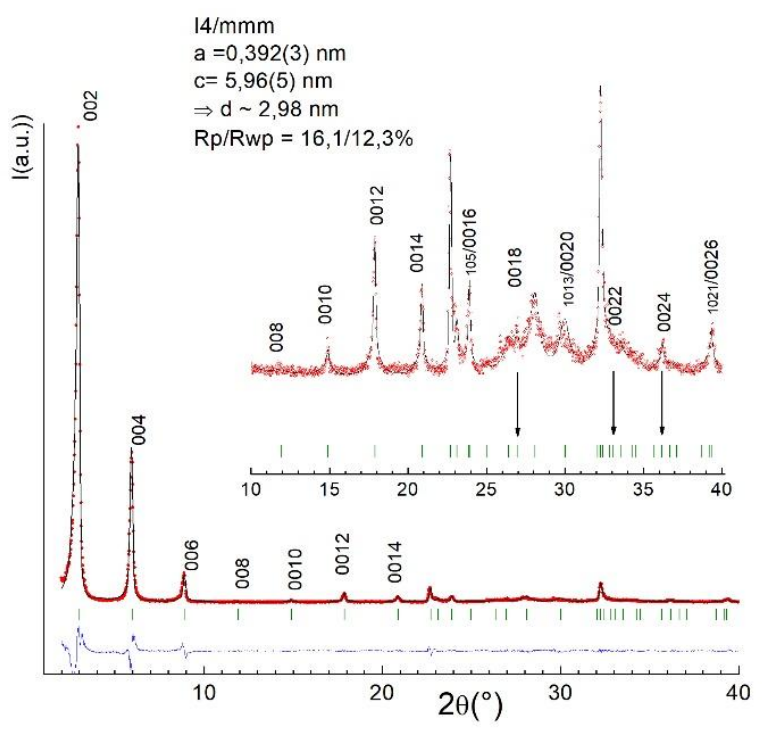

(a)

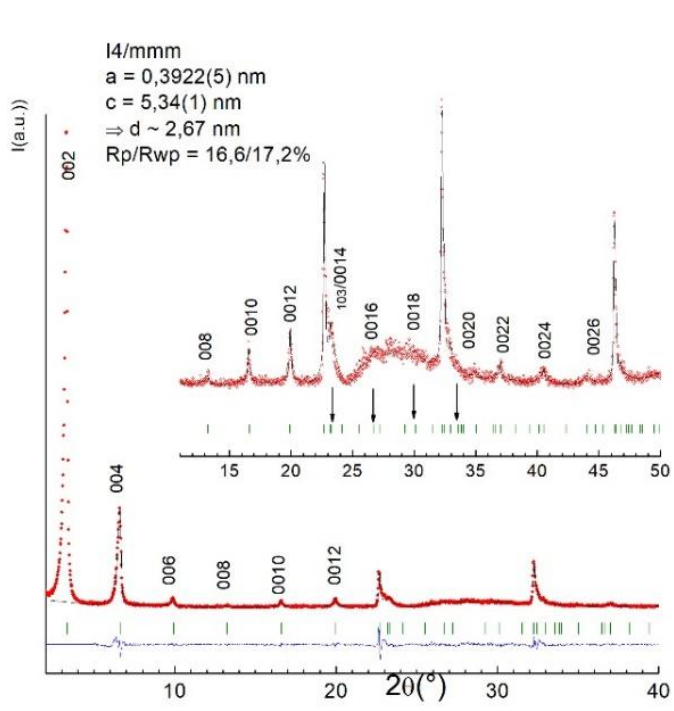

(b)

Figure 2. Profile analysis of the XRD pattern of (a) PBA3-HST and (b) PBA2-HST: experimental X-ray diffraction (circles), calculated (line), Bragg reflections (ticks), and difference profiles. Refinement in a tetragonal cell with $14 / \mathrm{mmm}$ space group. Extended region $10-40 / 50^{\circ}(2 \theta)$ showing all 001 diffraction lines. Reliability factors $R p / w p$.

In order to precise the arrangements of the PBA molecules which lead to different basal spacings, one-dimensional (1D) electron density profiles along the $c$-staking direction were determined for PBA2-HST and PBA3-HST. Indeed, the large number of 00/ diffraction lines, up to thirteen visible, allowed us to probe the structure of the interlayer space by the calculation of a one-dimensional electron density maps from the analysis of integrated intensities extracted from the above Le Bail profile decompositions and Fourier transformation. This approach has been applied successfully to the structural characterization of many intercalative nanohybrids.[28-34]

As shown in Fig. 3a, peaks on the 1D plot for PBA3-HST match perfectly with a bilayer arrangement of PBA molecule, in particular the minimum in the center. The most intense peaks are due to the perovskite layers containing $\mathrm{Sr}$, Ta and Bi elements (Fig. S4). The amino groups together with water molecules cause small maxima at the outer parts of the interlayer space at a distance of $~ 3.0 \AA$ from the inorganic layers which is consistent with hydrogen bond interactions. The central minimum framed by two maxima supports the bilayer arrangement with the two phenyl rings positioned on either side of the center. For PBA2-HST (Fig. 3b), peaks of higher electron densities are observed in the interlayer space indicating more compactly arranged PBA molecules. The two maxima are nearer of the center which suggests closely spaced phenyl rings. 


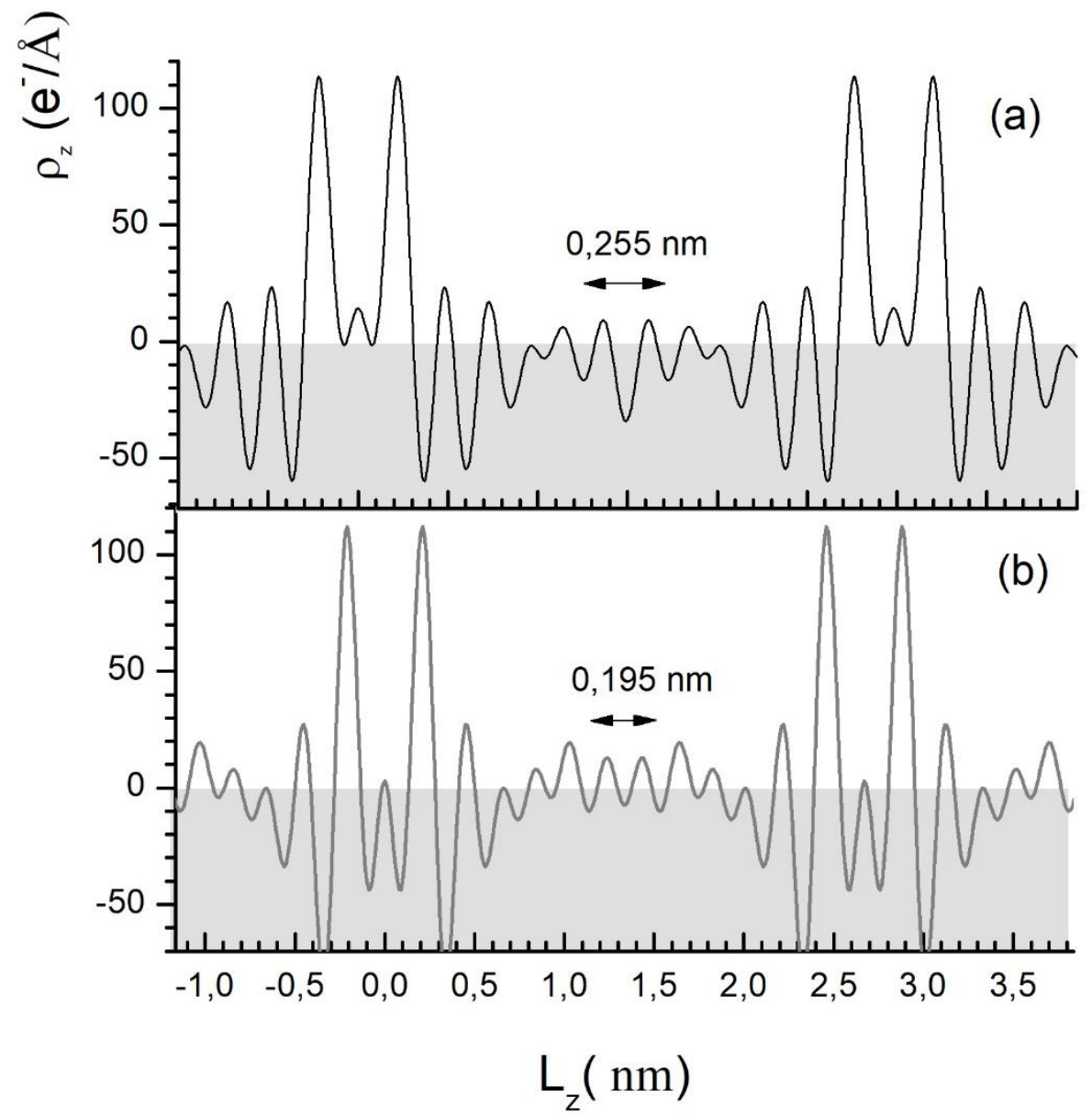

Figure 3. One-dimensional electron density projected along the c-stacking axis for(a) PBA2-HST and (b)PBA3-HST

Considering all the integrated intensities extracted from Le Bail fitting for PBA3-HST, we attempted to calculate the difference Fourier map after entering the known part of the structure i.e. the perovskite layer and assuming that the phases are controlled by the heavy atoms present in these layers. Such a difference map may help to highlight regions of low electron density associated with light atoms such as interlayer species.[35,36]

As can be seen in Figure 4b, the electron density in the interlayer space of PBA3-HST sample is quite low but nevertheless shows a distribution in different planes perpendicular to the $c$ stacking direction and the $z$ coordinates are consistent with the positions of the maxima noted on the 1D plot. A more or less important spreading of the density is observed for each of these planes indicating an orientation disorder of PBA molecule.

This result is then compared to a calculated Fourier map (Fig 4d) considering a structural model based on PBA molecules arranged head to tail with the butylamine chain inclined of $\sim 30^{\circ}$ with respect to the normal of the perovskite layers, which is typical of the angle observed in the case of aliphatic amines.[13]The nitrogen atom of the amine function chosen to express the rigid body was placed on the 4-fold axis $(4 \mathrm{~mm})$ in vertical alignment with the position of Sr atoms with a site occupancy of $1 / 4$ and at a distance of $~ 3.7 \AA$ from the HST layer, consistently with the formation of moderate hydrogen bonds. Phenyl rings of adjacent molecules are separated by $\sim 3.5 \AA$, in agreement with the observed interchain distance in the case of purely bilayer arrangement of aliphatic chains.[37] The comparison between this calculated Fourier map derived from this structural model and the difference Fourier map discussed above derived from $\mathrm{F}_{\mathrm{obs}}$ shows strong similarities which somehow confirms the 
structural model proposed. Of course, water molecules must be added and are most certainly located near the HST layer forming hydrogen bonding therewith and with the surrounding amino groups.

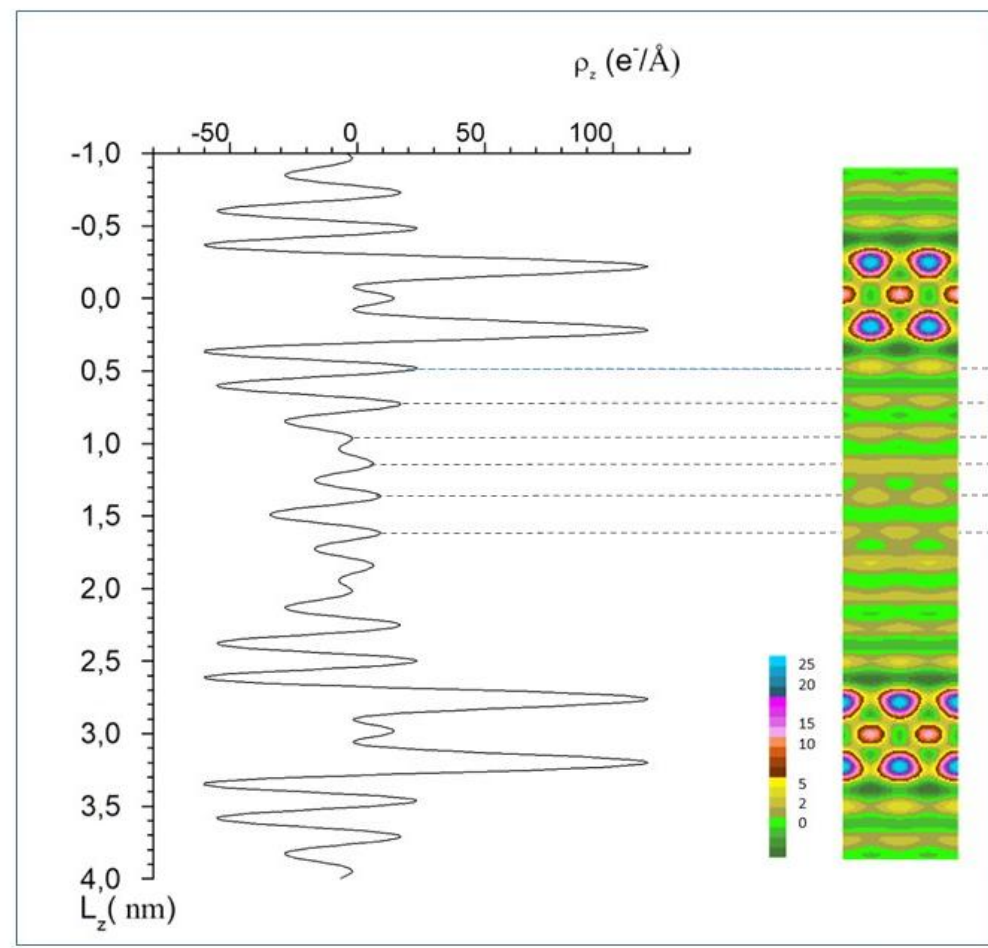

(a)

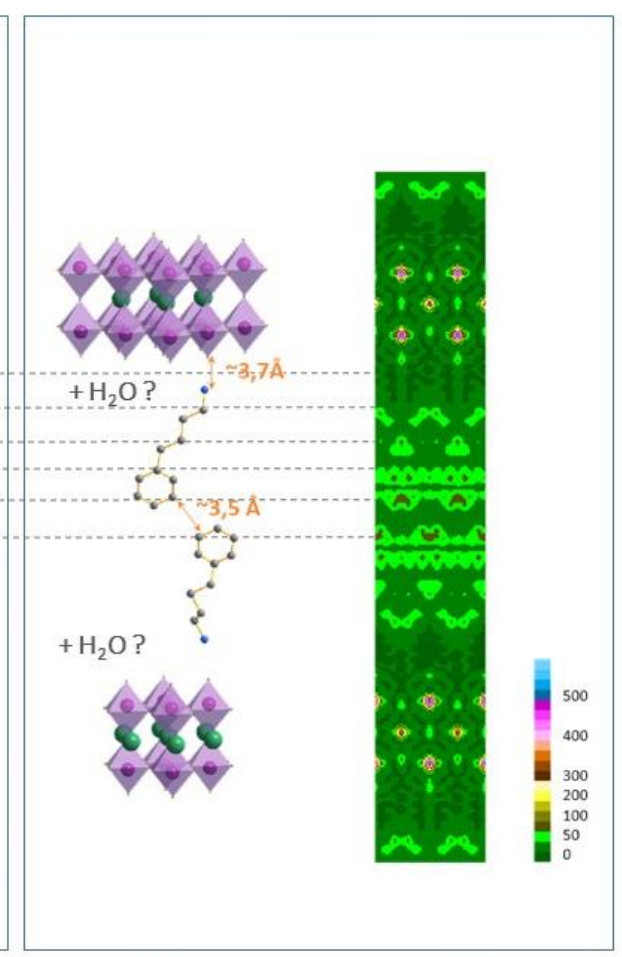

(c) (d)

Figure 4. Structural model for PBA3-HST deduced from:

(a) one-dimensional electron density projected along the c-stacking axis and (b) Difference Fourier (contoured) map summed from 0 to 1 along the a-axis; the electron density scale(e-/A) is given on the right. Both were calculated from the profile refinement of the XRD data; the phases and structure factors were computed from the known structure of the perovskite layers.

(d) Theoretical Fourier map calculated from the structural model proposed(c)

\subsection{Spectroscopic investigation}

IR spectra are very similar for the three phases (Fig. 5). The sharp $\mathrm{N}-\mathrm{H}$ stretching bands around $3300 \mathrm{~cm}^{-1}$ for the free ligand are greatly reduced in the hybrid compounds and a new $\mathrm{N}-\mathrm{H}$ stretching band appears at $2520 \mathrm{~cm}^{-1}$, which indicates the protonation of the amine group. The signals of the aromatic group at 3062 and $3026 \mathrm{~cm}^{-1}$ and the signals of $\mathrm{C}-\mathrm{C}$ bond and $\mathrm{C}-\mathrm{N}$ bond between $1500 \mathrm{~cm}^{-1}$ and $1700 \mathrm{~cm}^{-1}$ are clearly observed. The antisymmetric and symmetric stretching vibration bands of $\mathrm{CH}_{2}$ groups can also clearly be observed. The values of $v_{s}\left(\mathrm{CH}_{2}\right), v_{\text {as }}\left(\mathrm{CH}_{2}\right)$ and $\delta\left(\mathrm{CH}_{2}\right)$ for the three compounds are collected in Table 2 . The antisymmetric stretching bond $v_{\text {as }}\left(\mathrm{CH}_{2}\right)$ decreases from $2929.6 \mathrm{~cm}^{-1}$ to $2925.5 \mathrm{~cm}^{-1}$ and further to $2920.5 \mathrm{~cm}^{-1}$ for PBA1-HST, PBA2-HST and PBA3-HST respectively. In the present case, as seen above, there is no clear difference in the packing densities of the methylene chains. Therefore, the only explanation for a variation in the position of $\mathrm{vas}_{\mathrm{as}}\left(\mathrm{CH}_{2}\right)$ is the gauche/trans conformation ratio.[38] It has indeed been shown that the lower $\mathrm{vas}_{\text {as }}\left(\mathrm{CH}_{2}\right)$ frequencies correspond to highly ordered all-trans conformations whereas higher frequencies indicate a larger amount of gauche conformations along the hydrocarbon chain, and an increase of chain disorder.[38] Therefore, the above results indicate that the number 
of all-trans conformations increases and the number of gauche conformations (disorder) decreases along with the increase of the interlayer distance of PBA-intercalated products (i.e. in the order PBA1-HST, PBA2-HST, PBA3-HST), in line with the XRD study.

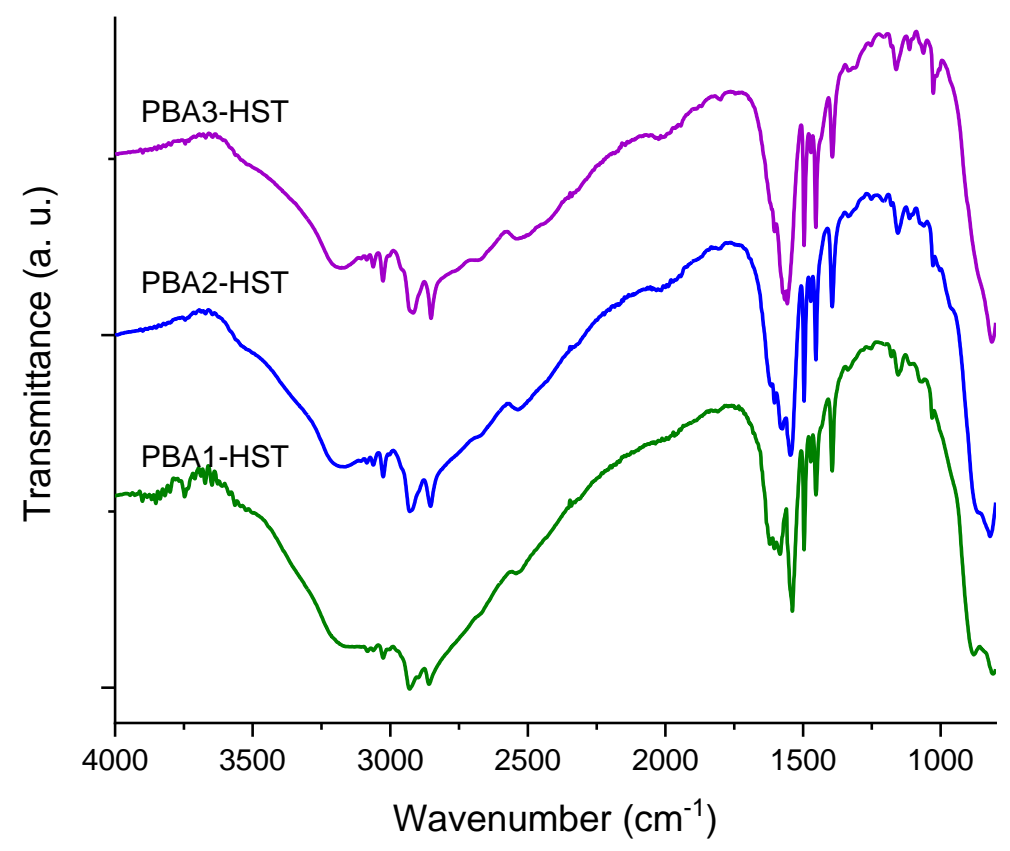

Figure 5. Zoom of the infrared spectra of PBA1-HST (green), PBA2-HST (blue) and PBA3-HST (purple) in the $4000-800 \mathrm{~cm}^{-1}$ region.

Table 2. Position of the IR absorption bands of the $\mathrm{CH}_{2}$ groups in PBA1-HST, PBA2-HST and PBA3-HST.

\begin{tabular}{|c|c|c|c|}
\hline Product & $\begin{array}{c}\mathbf{V}_{\text {as }}\left(\mathbf{C H}_{\mathbf{2}}\right) \\
\left(\mathbf{c m}^{-1}\right)\end{array}$ & $\begin{array}{c}\mathbf{V}_{\mathbf{s}}\left(\mathbf{C H}_{\mathbf{2}}\right) \\
\left(\mathbf{c m}^{-1}\right)\end{array}$ & $\begin{array}{c}\mathbf{\delta}\left(\mathbf{C H}_{\mathbf{2}}\right) \\
\left(\mathbf{c m}^{-1}\right)\end{array}$ \\
\hline PBA1-HST & 2929.6 & 2860.1 & 1471.8 \\
\hline PBA2-HST & 2925.5 & 2853.7 & 1471.8 \\
\hline PBA3-HST & 2920.5 & 2851.9 & 1471.1 \\
\hline
\end{tabular}

The bending vibration $\delta\left(\mathrm{CH}_{2}\right)$ hardly changes for PBA1-HST, PBA2-HST and PBA3-HST, neither in position nor in intensity. The high frequency of this band $\left(c a .1472 \mathrm{~cm}^{-1}\right)$ indicates that PBA molecules in the three phases have at least partially ordered methylene chains.[38]

${ }^{13} \mathrm{C}$ CP/MAS solid state NMR spectroscopy was also performed. The spectra display a high degree of similarity (Fig. 6). Signals attributed to carbon A and carbon B appear at $40 \mathrm{ppm}$ and $29 \mathrm{ppm}$ respectively for the three compounds whereas they appear at $42.1 \mathrm{ppm}$ and $33.4 \mathrm{ppm}$ respectively products for PBA in solution in $\mathrm{D}_{2} \mathrm{O}$. This up-field shifts of $\mathrm{A}$ and $\mathrm{B}$ carbon signals confirm the conversion of $-\mathrm{NH}_{2}$ groups to $-\mathrm{NH}_{3}{ }^{+}$groups.[39-42] On the contrary, the position of the signals of the aliphatic carbons $C$ and $D$ and of the aromatic carbons $E, F, F^{\prime}, G, G^{\prime}$ and $H$ are not modified with respect to the spectrum of PBA in solution. Finally, it is worth noticing that all signals are slightly split (except the aromatic $F$, $F^{\prime}, G$ and $G^{\prime}$, because of the fast averaging of the chemical shifts due to electron delocalization). This may come from slightly different arrangements of the molecules in the interlayer spacing. Despite the partial interdigitation evidenced for PBA3-HST by 1D electron 
density map, no effect of this interdigitation (likely due to $\pi$-stacking of the aromatic rings) could be observed on the ${ }^{13} \mathrm{C} C P / M A S$ solid state NMR spectra.

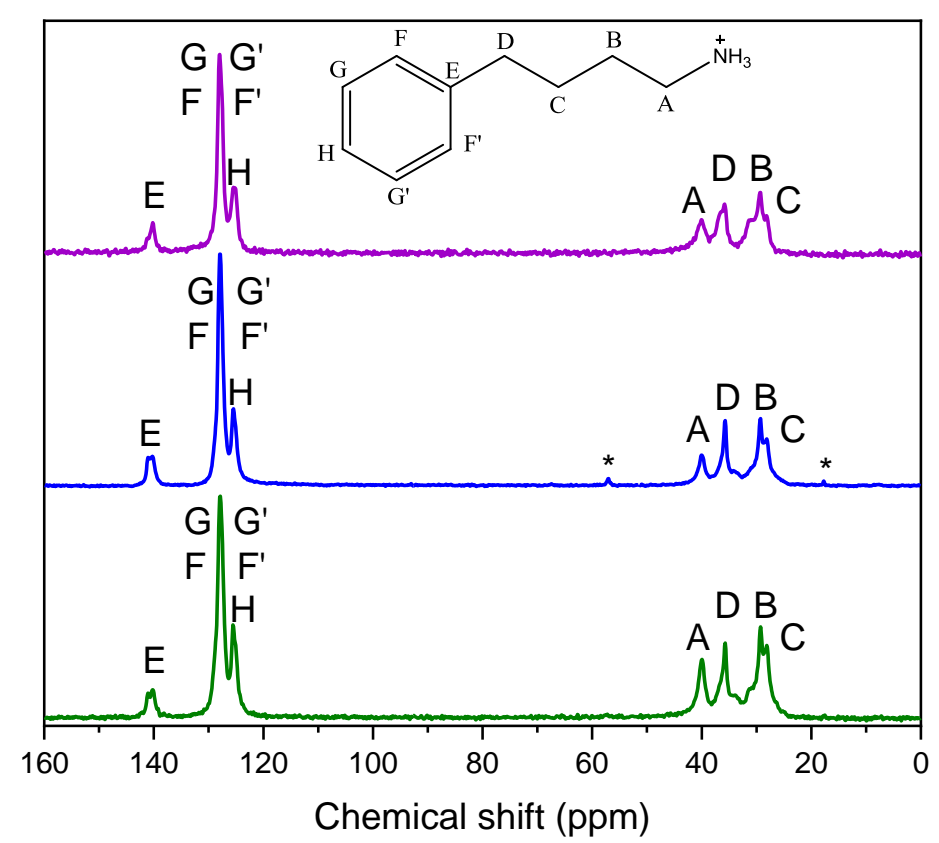

Figure 6. Solid-state ${ }^{13} \mathrm{C} C P / M A S N M R$ spectra of PBA1-HST (green, bottom), PBA2-HST (blue, middle) and PBA3-HST (purple, top) (asterisk indicate the presence of a small residual amount of ethanol).

It thus appears that the arrangement of the PBA molecules is strongly dependent of the synthesis conditions. Partial interdigitation of the phenylbutylamine is favoured for short reaction times, whereas when a longer reaction time (and longer heating time, the two parameters being difficult to decorrelate) is used, the obtained phase is better crystallized, with a complete bi-layer arrangement of the interlayer molecules, without any interdigitation. The choice of another precursor, $\mathbf{C}_{2} \mathbf{N}-\mathbf{H S T}$ instead of HST, and short reaction times leads to a somehow intermediate phase.

\subsection{Influence of reaction parameters: temperature, reaction time, and quantity of PBA used}

To study the influence of the reaction temperature, a series of reactions were performed using microwave assisted reactions, using the same experimental procedure as for PBA1HST, at $80^{\circ} \mathrm{C}, 130^{\circ} \mathrm{C}$ (PBA1-HST) or $160^{\circ} \mathrm{C}$. Fig. 7 shows the XRD patterns of HST and the obtained reaction products. The XRD pattern of the compound obtained at $80^{\circ} \mathrm{C}$ is essentially identical to the one of HST (with a slightly larger interlayer distance $(1.00 \mathrm{~nm}$ ) and a decreased crystallinity), indicating that the intercalation reaction did not take place. At higher temperatures, the interlayer distance increases from that of HST $(0.98 \mathrm{~nm})$ to 2.20 $\mathrm{nm}\left(130^{\circ} \mathrm{C}, \mathrm{PBA} 1-\mathrm{HST}\right)$ and up to $2.65 \mathrm{~nm}$ for the compound obtained at $160^{\circ} \mathrm{C}$. Yet for this last compound, diffraction lines corresponding to the ones of HST (indicated by an asterisk) indicate the presence of the starting material in the final compound, likely due to a partial degradation of the obtained compound, as marked also by the decreased intensity of the 001 diffraction lines with respect to the characteristic reflections $(100)$ at $22.68^{\circ},(110)$ at $32.59^{\circ}$, 
and (200) at $\left.46.32^{\circ}(\mathrm{Cu} \mathrm{K} \alpha 1)\right)$. Despite this degradation, it appears that higher reaction temperatures favour intercalation and an increase of the interlayer distance. Yet even at $160^{\circ} \mathrm{C}$, the interlayer distance of the obtained product does not reach the one of PBA3-HST $(3.0 \mathrm{~nm})$, underlining the crucial role played by the reaction time.

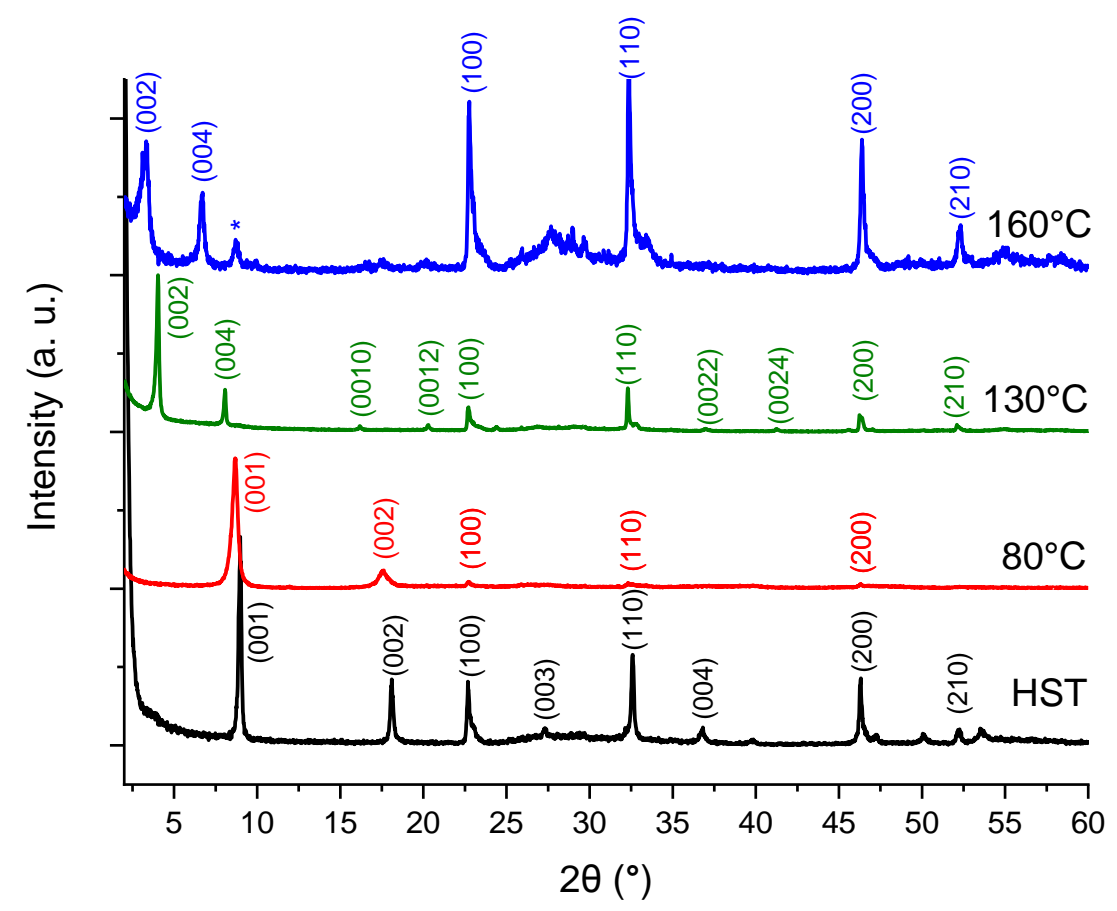

Figure 7. XRD patterns of $\mathrm{HST}$ and its reaction products with $P B A$ at $80^{\circ} \mathrm{C}, 130^{\circ} \mathrm{C}$ and $160^{\circ} \mathrm{C}$. Indexation of the peaks of HST comes from reference [22]. For the indexation of the peaks of the other compounds, see Figure 2.

The same reaction was then performed, at $130^{\circ} \mathrm{C}$, but using different reaction times $(0.5 \mathrm{~h}$, $1.5 \mathrm{~h}$ (PBA1-HST), $3 \mathrm{~h}$ and $4.5 \mathrm{~h}$ ). Fig. 8 shows the XRD patterns of HST and the obtained reaction products. The XRD pattern of the compound obtained after $0.5 \mathrm{~h}$ shows an increase of the interlayer distance $(2.20 \mathrm{~nm}$, identical to that of PBA1-HST) but indicates also the presence of another compound with an interlayer distance of $1.00 \mathrm{~nm}$, likely corresponding to hydrated HST. For longer reaction times, the interlayer distances of the reaction products increase from $2.20 \mathrm{~nm}$ (PBA1-HST) to $2.72 \mathrm{~nm}$. Yet, for reaction times longer than $1.5 \mathrm{~h}$, the crystallinity decreases and/or multiphasic compounds are obtained. Longer reaction times thus favour a larger interlayer distances, revealing that PBA1-HST $(d=2.20 \mathrm{~nm})$ is in fact a kinetic product. Yet the reaction mechanism from PBA1-HST to the thermodynamic compound PBA3-HST $(d=3.00 \mathrm{~nm})$ is not straightforward. One hypothesis is that interstratification (second staging) phenomenon is at stake during the reaction process, [1820] yet such a phenomenon could not be evidenced clearly in the present work. Finally, it is worth mentioning that PBA1-HST is stable for months in the solid state, without any reduction of the crystallinity nor any change of the interlayer distance. 


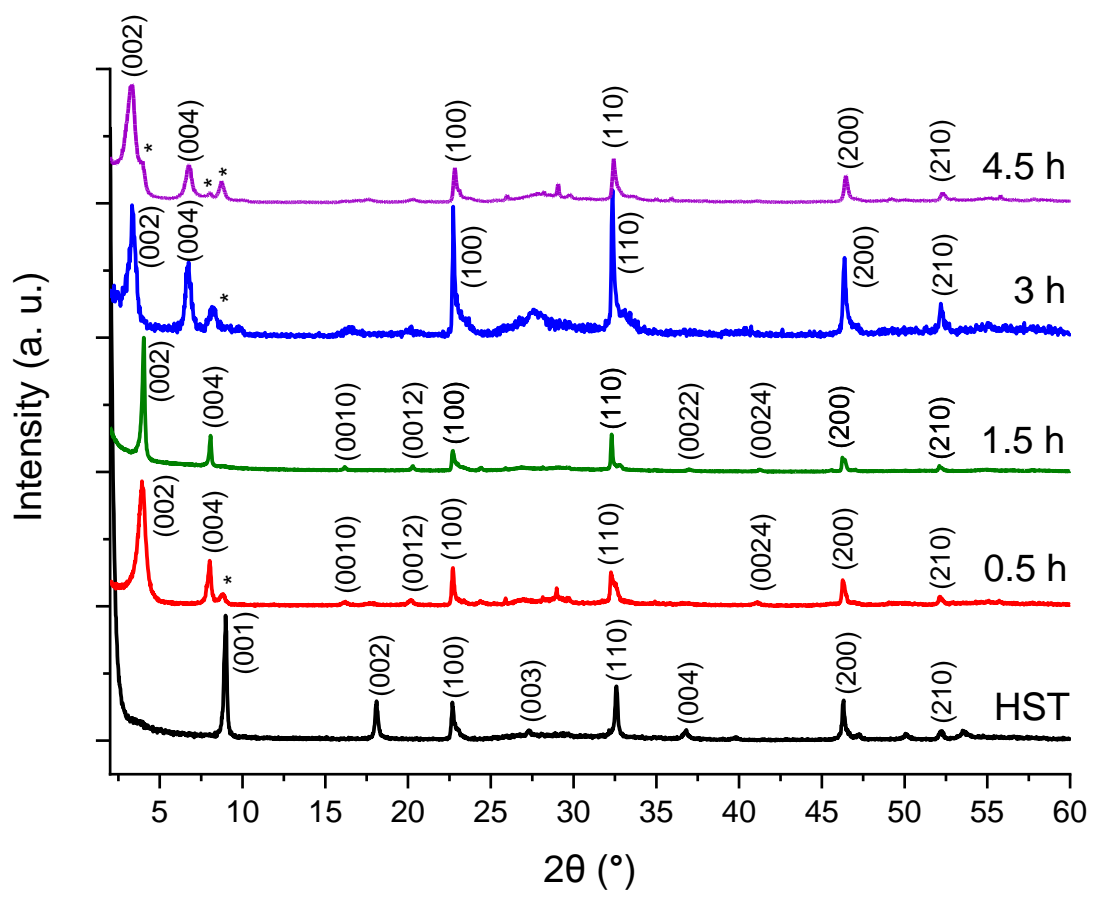

Figure 8. XRD pattern of HST and its reaction products with PBA at $130^{\circ} \mathrm{C}$ with $0.5 \mathrm{~h}, 1.5 \mathrm{~h}, 3 \mathrm{~h}$ and $4.5 \mathrm{~h}$ reaction times. Asterisks indicate diffraction lines attributed to an impurity phase (see text).

Finally, the influence of the molar ratio between HST and PBA and (HST:PBA) has been investigated $\left(1,2,5,10,50,100\right.$, and 200). The microwave assisted $\left(130{ }^{\circ} \mathrm{C}, 1.5 \mathrm{~h}\right)$ reactions were always performed in a THF/ $\mathrm{H}_{2} \mathrm{O}$ mixture $(5: 1 \mathrm{v}: \mathrm{v})$ as for the synthesis of PBA1-HST. XRD patterns show that the interlayer distances of reaction products are always around $2.2 \mathrm{~nm}$ except for very low quantities of PBA (HST:PBA $=1: 1$ and 1:2) for which new different phases were obtained (at $1.25 \mathrm{~nm}$ for the ratio 1:1, and at around $3 \mathrm{~nm}$ for the ratio 1:2, most probably corresponding to swelling) (Fig. 9). In conclusion, there is not an obvious effect of the molar ration between PBA and HST on the interlayer distance. We retrieve here the result described for microwave-assisted insertion of aliphatic amines which requires a large excess of amine (about $\times 100)$. $[13,14]$ 


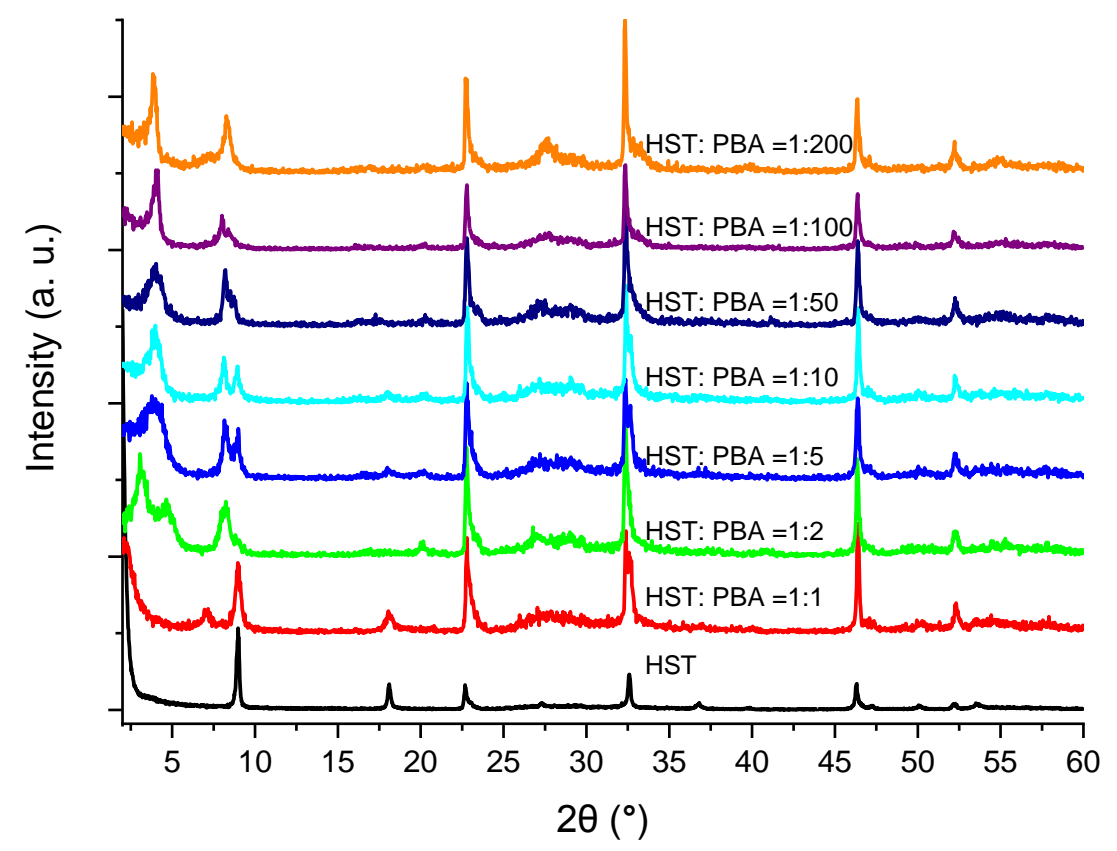

Figure 9. XRD pattern of $\mathrm{HST}$ and its reaction products at $130^{\circ} \mathrm{C}$ with various $\mathrm{HST}$ :PBA ratios. (The relatively low crystallinity of the compounds obtained here is due to a low crystallinity of the HST batch used for this set of experiments. Our experience shows that the crystallinity of HST influence the crystallinity of the reaction products, but not the reactivity of HST nor the nature of the obtained products. [43])

The possibility of mutual conversion between the three obtained products (PBA1-HST, PBA2-HST and PBA3-HST) has been investigated by using solvent treatment. When PBA2HST $(50 \mathrm{mg})$ is stirred in acetone $(15 \mathrm{~mL})$ at room temperature overnight, the interlayer distance increases from $2.67 \mathrm{~nm}$ to $2.95 \mathrm{~nm}$ (compound a), very close to the one of PBA3HST (Fig. 10). The reverse conversion is achieved by stirring compound a in water $(15 \mathrm{~mL})$ at room temperature overnight. The obtained product, compound $b$, presents an interlayer distance of $2.62 \mathrm{~nm}$, very close to the one of PBA2-HST. Yet this reverse process is accompanied by a partial hydrolysis of the compound. It thus appears that the mutual conversion between PBA2-HST and PBA3-HST can be realized by simple solvent treatments. Such solvent treatment-induced modification of the interlayer spacing has already been reported in a layered $\mathrm{Zn}$ hydroxide functionalized by dodecylsulfate.[18] In this case, methanol induces a decrease of the number of intercalated molecules, which is accompanied by a modification of the structure of the inorganic layers. In the present case, the solvent treatment acts directly and only on the interactions between interleaved molecules, as reported by Fujita and Awaga in the case of a layered $\mathrm{Cu}$ hydroxide functionalized by 8-((p-(phentlazo)phenyl)oxy)octanoate.[44] It is worth noticing that in this latter case just like in the present work, the molecules at stake are made of a flexible aliphatic chain and terminal aromatic group. This scheme might indeed favour a controllable interdigitation phenomenon.

Unfortunately, up to now we have not found the proper conditions to realize the mutual conversion between PBA1-HST and PBA2-HST or between PBA1-HST and PBA3-HST. 


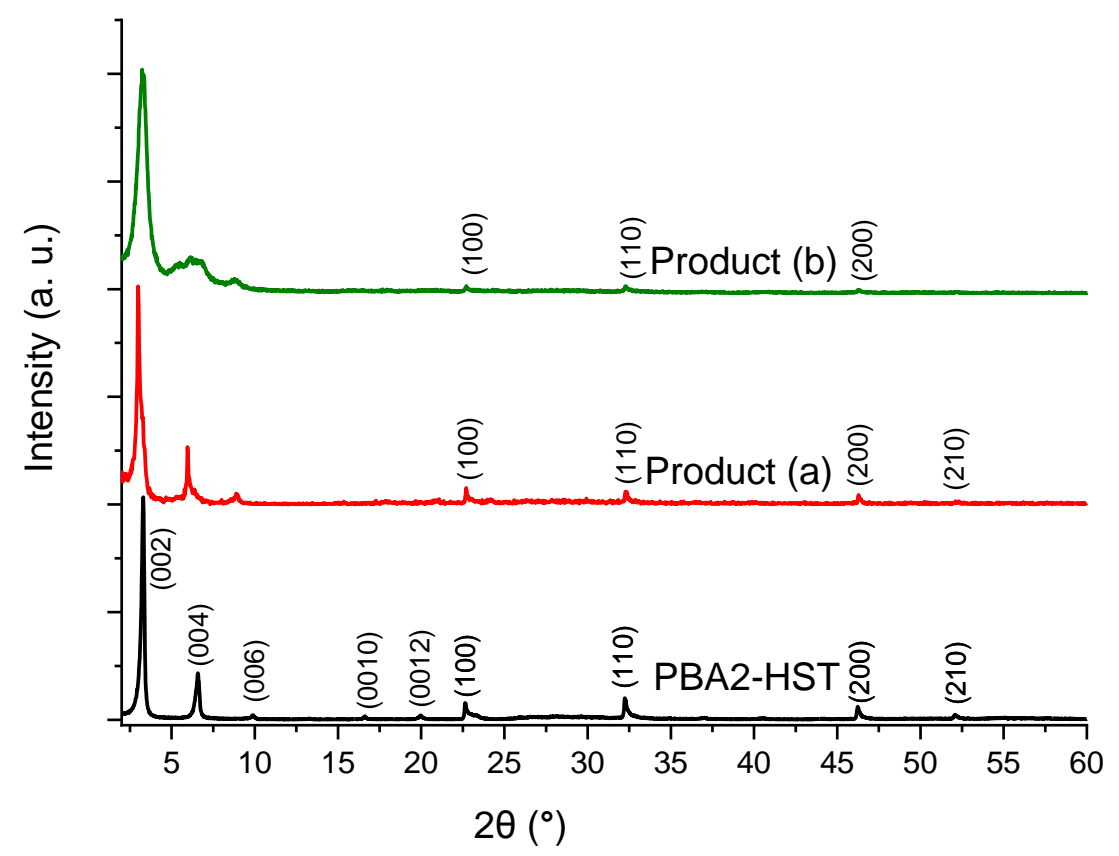

Figure 10. XRD patterns illustrating the mutual conversions between PBA2-HST and PBA3-HST. Product (a): PBA2-HST was stirred in acetone at room temperature overnight. Product (b): Product (a) was stirred in water at room temperature overnight.

\section{Conclusion}

We have described the synthesis of a layered Ta oxide perovskite functionalized by phenylbutylamine molecules. Depending on the reaction conditions, compounds with different interlayer spacings are obtained. Short reaction times, obtained using microwaveactivated reactions lead to compounds with a small interlayer spacing, whereas long reaction times, using classical solvothermal reactions provides compounds with a much larger interlayer spacing. Whereas no change in composition (organic loading) could be evidenced, careful analysis of the XRD patterns and calculation of the 1D electron density profiles allows to precise the degree of interdigitation of the molecules in the interlayer space, revealing an overlap of the aromatic cycles for short interlayer distances. Moreover, XRD analysis and IR spectroscopy show the higher disorder of the organic molecules in the interdigitated configuration. Using a different precursor, a phase possessing an intermediate interlayer distance could be isolated. Yet the reaction mechanism from the short interlayer distance phase (kinetic product) to the large interlayer distance phase (thermodynamic product) remains unknown.

This work adds a new perspective to the ever-growing use of microwave irradiation for the synthesis of organic-inorganic layered hybrids. Indeed, microwave irradiation not only enables to synthesize much faster compounds that can be obtained classically, but also enables to obtain new pure kinetic phases, inaccessible by other means. Such an approach, reinforced by the careful design of the inserted molecules, may allow to tailor at will new hybrids layered compounds with precise applications.

\section{Acknowledgements}

The authors thank the CNRS, the Université de Strasbourg, the Université de ClermontFerrand and the Agence Nationale de la Recherche (ANR contract ANR-14-CE07-0004-01) for 
financial support and the Chemistry Department of the CNRS and the Région Alsace for the Ph.D. grant of Y.W. The authors thank Dr. M. Lenertz for fruitful discussions and D. Burger and C. Kiefer for technical assistance.

\section{Supplementary information}

TGA and TDA curves, representative SEM image and calculated electron density profile for BST.

\section{Bibliography}

[1] P. Ganter, L.M. Schoop, M. Däntl, B.V. Lotsch, Vapor-Phase Amine Intercalation for the Rational Design of Photonic Nanosheet Sensors, Chem. Mater. 30 (2018) 2557-2565. doi:10.1021/acs.chemmater.7b04828.

[2] C. Ziegler, S. Werner, M. Bugnet, M. Wörsching, V. Duppel, G.A. Botton, C. Scheu, B.V. Lotsch, Artificial Solids by Design: Assembly and Electron Microscopy Study of Nanosheet-Derived Heterostructures, Chem. Mater. 25 (2013) 4892-4900. doi:10.1021/cm402950b.

[3] L. Wang, T. Sasaki, Titanium Oxide Nanosheets: Graphene Analogues with Versatile Functionalities, Chem. Rev. 114 (2014) 9455-9486. doi:10.1021/cr400627u.

[4] E. Coronado, C. Martí-Gastaldo, E. Navarro-Moratalla, A. Ribera, S.J. Blundell, P.J. Baker, Coexistence of superconductivity and magnetism by chemical design, Nature Chem. 2 (2010) 1031-1036. doi:10.1038/nchem.898.

[5] A.H. Khan, S. Ghosh, B. Pradhan, A. Dalui, L.K. Shrestha, S. Acharya, K. Ariga, TwoDimensional (2D) Nanomaterials towards Electrochemical Nanoarchitectonics in EnergyRelated Applications, Bull. Chem. Soc. Jpn. 90 (2017) 627-648. doi:10.1246/bcsj.20170043.

[6] C. Tan, X. Cao, X.-J. Wu, Q. He, J. Yang, X. Zhang, J. Chen, W. Zhao, S. Han, G.-H. Nam, M. Sindoro, H. Zhang, Recent Advances in Ultrathin Two-Dimensional Nanomaterials, Chem. Rev. 117 (2017) 6225-6331. doi:10.1021/acs.chemrev.6b00558.

[7] B.-W. Li, M. Osada, Y. Ebina, S. Ueda, T. Sasaki, Coexistence of Magnetic Order and Ferroelectricity at 2D Nanosheet Interfaces, J. Am. Chem. Soc. 138 (2016) 7621-7625. doi:10.1021/jacs.6b02722.

[8] R. Ma, T. Sasaki, Nanosheets of Oxides and Hydroxides: Ultimate 2D Charge-Bearing Functional Crystallites, Adv. Mater. 22 (2010) 5082-5104. doi:10.1002/adma.201001722.

[9] R. Uppuluri, A.S. Gupta, A.S. Rosas, T.E. Mallouk, Soft chemistry of ion-exchangeable layered metal oxides, Chem. Soc. Rev. 47 (2018) 2401-2430. doi:10.1039/C7CS00290D.

[10] R.E. Schaak, T.E. Mallouk, Perovskites by Design: A Toolbox of Solid-State Reactions, Chem. Mater. 14 (2002) 1455-1471. doi:10.1021/cm010689m.

[11] K.G. Sanjaya Ranmohotti, E. Josepha, J. Choi, J. Zhang, J.B. Wiley, Topochemical Manipulation of Perovskites: Low-Temperature Reaction Strategies for Directing Structure and Properties, Adv. Mater. 23 (2011) 442-460. doi:10.1002/adma.201002274.

[12] J. Gopalakrishnan, T. Sivakumar, K. Ramesha, V. Thangadurai, G.N. Subbanna, Transformations of Ruddlesden-Popper Oxides to New Layered Perovskite Oxides by Metathesis Reactions, J. Am. Chem. Soc. 122 (2000) 6237-6241. doi:10.1021/ja9914644.

[13] Y. Wang, E. Delahaye, C. Leuvrey, F. Leroux, P. Rabu, G. Rogez, Efficient MicrowaveAssisted Functionalization of the Aurivillius-Phase $\mathrm{Bi}_{2} \mathrm{SrTa}_{2} \mathrm{O}_{9}$, Inorg. Chem. 55 (2016) 4039-4046. doi:10.1021/acs.inorgchem.6b00338. 
[14] S. Akbarian-Tefaghi, E. Teixeira Veiga, G. Amand, J.B. Wiley, Rapid Topochemical Modification of Layered Perovskites via Microwave Reactions, Inorg. Chem. 55 (2016) 1604-1612. doi:10.1021/acs.inorgchem.5b02514.

[15] J.R. Boykin, L.J. Smith, Rapid Microwave-Assisted Grafting of Layered Perovskites with n-Alcohols, Inorg. Chem. 54 (2015) 4177-4179. doi:10.1021/ic503001w.

[16] S. Akbarian-Tefaghi, J.B. Wiley, Microwave-assisted routes for rapid and efficient modification of layered perovskites, Dalton Trans. 47 (2018) 2917-2924. doi:10.1039/C7DT03865H.

[17] Y. Wang, E. Delahaye, C. Leuvrey, F. Leroux, P. Rabu, G. Rogez, Post-Synthesis Modification of the Aurivillius Phase $\mathrm{Bi}_{2} \mathrm{SrTa}_{2} \mathrm{O}_{9}$ via In Situ Microwave-Assisted "Click Reaction," Inorg. Chem. 55 (2016) 9790-9797. doi:10.1021/acs.inorgchem.6b01600.

[18] J. Demel, J. Hynek, P. Kovář, Y. Dai, C. Taviot-Guého, O. Demel, M. Pospíšil, K. Lang, Insight into the Structure of Layered Zinc Hydroxide Salts Intercalated with Dodecyl Sulfate Anions, J. Phys. Chem. C. 118 (2014) 27131-27141. doi:10.1021/jp508499g.

[19] Y. Du, D. O'Hare, Observation of Staging during Intercalation in Layered $\alpha$-Cobalt Hydroxides: A Synthetic and Kinetic Study, Inorg. Chem. 47 (2008) 11839-11846. doi:10.1021/ic801639e.

[20] A.M. Fogg, J.S. Dunn, D. O'Hare, Formation of Second-Stage Intermediates in AnionExchange Intercalation Reactions of the Layered Double Hydroxide $\left[\mathrm{LiAl}_{2}(\mathrm{OH})_{6}\right] \mathrm{Cl}_{2} \cdot \mathrm{H}_{2} \mathrm{O}$ As Observed by Time-Resolved, in Situ X-ray Diffraction, Chem. Mater. 10 (1998) 356-360. doi:10.1021/cm970553h.

[21] A.D. Rae, J.G. Thompson, R.L. Withers, Structure refinement of commensurately modulated bismuth strontium tantalate, $\mathrm{Bi}_{2} \mathrm{SrTa}_{2} \mathrm{O}_{9}$, Acta Cryst. Sect. B. 48 (1992) 418428. doi:10.1107/S0108768192001654.

[22] Y. Tsunoda, M. Shirata, W. Sugimoto, Z. Liu, O. Terasaki, K. Kuroda, Y. Sugahara, Preparation and HREM Characterization of a Protonated Form of a Layered Perovskite Tantalate from an Aurivillius Phase $\mathrm{Bi}_{2} \mathrm{SrTa}_{2} \mathrm{O}_{9}$ via Acid Treatment, Inorg. Chem. 40 (2001) 5768-5771. doi:10.1021/ic010266m.

[23] J. Rodriguez-Carvajal, Recent developments of the program FULLPROF, Commission on Powder Diffraction (IUCr) Newsletter. (2001) 12-19.

[24] P. Thompson, D.E. Cox, J.B. Hastings, Rietveld refinement of Debye-Scherrer synchrotron X-ray data from $\mathrm{Al}_{2} \mathrm{O}_{3}$, Journal of Applied Crystallography. 20 (1986) 79-83. doi:10.1107/S0021889887087090.

[25] A.J. Jacobson, M.S. Whittingham, Intercalation Chemistry, Academic Press, New-York, 1982.

[26] P.J. Ollivier, T.E. Mallouk, A "Chimie Douce" Sythesis of Perovskite-Type $\mathrm{SrTa}_{2} \mathrm{O}_{6}$ and $\mathrm{SrTa}_{2-\mathrm{x}} \mathrm{Nb}_{\mathrm{x}} \mathrm{O}_{6}$, Chem. Mater. 10 (1998) 2585-2587. doi:10.1021/cm9802144.

[27] M.-P. Crosnier-Lopez, F.L. Berre, J.-L. Fourquet, The layered perovskite $\mathrm{K}_{2} \mathrm{SrTa}_{2} \mathrm{O}_{7}$ :hydration and $\mathrm{K}^{+} / \mathrm{H}^{+}$ion exchange, J. Mater. Chem. 11 (2001) 1146-1151. doi:10.1039/B005755J.

[28] J.-H. Choy, S.-J. Hwang, N.-G. Park, Intracrystalline Structure of Molecular Mercury Halide Intercalated in High-Tc Superconducting Lattice of $\mathrm{Bi}_{2} \mathrm{Sr}_{2} \mathrm{CaCu}_{2} \mathrm{O}_{y}$, J. Am. Chem. Soc. 119 (1997) 1624-1633. doi:10.1021/ja961993x.

[29] J.-H. Choy, Y.-I. Kim, S.-J. Hwang, Y. Muraoka, N. Ohnishi, K. Hiraga, P.V. Huong, HRTEM and Micro-Raman Studies on Superconducting-Superionic Conducting Nanohybrid, $\mathrm{Ag}_{1.17} \mathrm{I}_{1.54} \mathrm{Bi}_{2} \mathrm{Sr}_{2} \mathrm{CaCu}_{2} \mathrm{O}_{y}$, J. Phys. Chem. B. 104 (2000) 9086-9090. doi:10.1021/jp993096w. 
[30] R. Marangoni, C. Taviot-Guého, A. Illaik, F. Wypych, F. Leroux, Organic inorganic dye filler for polymer: Blue-coloured layered double hydroxides into polystyrene, Journal of Colloid and Interface Science. 326 (2008) 366-373. doi:10.1016/j.jcis.2008.06.030.

[31] T. Fujita, N. Iyi, T. Kosugi, A. Ando, T. Deguchi, T. Sota, Intercalation characteristics of rhodamine $6 \mathrm{G}$ in fluor-taeniolite; orientation in the gallery, Clays and Clay Minerals. 45 (1997) 77-84.

[32] T. Itoh, T. Shichi, T. Yui, H. Takahashi, Y. Inui, K. Takagi, Reversible Color Changes in Lamella Hybrids of Poly(diacetylenecarboxylates) Incorporated in Layered Double Hydroxide Nanosheets, J. Phys. Chem. B. 109 (2005) 3199-3206. doi:10.1021/jp045410e.

[33] D.-H. Park, J.-H. Yang, A. Vinu, A. Elzatahry, J.-H. Choy, X-ray diffraction and X-ray absorption spectroscopic analyses for intercalative nanohybrids with low crystallinity, Arabian Journal of Chemistry. 9 (2016) 190-205. doi:10.1016/j.arabjc.2015.07.007.

[34] Y.-J. Liu, J.L. Schindler, D.C. DeGroot, C.R. Kannewurf, W. Hirpo, M.G. Kanatzidis, Synthesis, Structure, and Reactions of Poly(ethylene oxide) $/ \mathrm{V}_{2} \mathrm{O}_{5}$ Intercalative Nanocomposites, Chem. Mater. 8 (1996) 525-534. doi:10.1021/cm950366o.

[35] B. Monteiro, S. Gago, F.A.A. Paz, R. Bilsborrow, I.S. Gonçalves, M. Pillinger, Investigation of Layered Double Hydroxides Intercalated by Oxomolybdenum Catecholate Complexes, Inorg. Chem. 47 (2008) 8674-8686. doi:10.1021/ic800420a.

[36] E. Káfuňková, C. Taviot-Guého, P. Bezdička, M. Klementová, P. Kovář, P. Kubát, J. Mosinger, M. Pospíšil, K. Lang, Porphyrins Intercalated in Zn/Al and Mg/Al Layered Double Hydroxides: Properties and Structural Arrangement, Chem. Mater. 22 (2010) 2481-2490. doi:10.1021/cm903125v.

[37] C. Rösner, G. Lagaly, Interlayer reactions of the silver molybdate $\mathrm{Ag}_{6} \mathrm{Mo}_{10} \mathrm{O}_{33}$, Journal of Solid State Chemistry. 53 (1984) 92-100. doi:10.1016/0022-4596(84)90231-7.

[38] R.A. Vaia, R.K. Teukolsky, E.P. Giannelis, Interlayer Structure and Molecular Environment of Alkylammonium Layered Silicates, Chem. Mater. 6 (1994) 1017-1022. doi:10.1021/cm00043a025.

[39] S. Tahara, T. Yamashita, G. Kajiwara, Y. Sugahara, Intercalation of a,w-Diaminoalkanes in the Interlamellar Space of the Protonated Form of the Layered Perovskite $\mathrm{H}_{1.8} \mathrm{Bi}_{0.2} \mathrm{Sr}_{0.8} \mathrm{Ta}_{2} \mathrm{O}_{7}$, Chemistry Letters. 35 (2006) 1292-1293.

[40] B. Kamieński, W. Schilf, T. Dziembowska, Z. Rozwadowski, A. Szady-Chełmieniecka, The ${ }^{15} \mathrm{~N}$ and ${ }^{13} \mathrm{C}$ solid state NMR study of intramolecular hydrogen bond in some Schiff's bases, Solid State Nuclear Magnetic Resonance. 16 (2000) 285-289. doi:10.1016/S09262040(00)00080-1.

[41] Y. Komori, Y. Sugahara, K. Kuroda, Intercalation of alkylamines and water into kaolinite with methanol kaolinite as an intermediate, Applied Clay Science. 15 (1999) 241-252. doi:10.1016/S0169-1317(99)00014-9.

[42] M. Wallau, J. Patarin, I. Widmer, P. Caullet, J.L. Guth, L. Huve, Room-temperature synthesis of crystalline solids in the system $\mathrm{ZnO}-\mathrm{P}_{2} \mathrm{O}_{5}-\mathrm{R}-\mathrm{H}_{2} \mathrm{O}$, with $\mathrm{R}$ being an alkylamine or an alkylammonium ion, Zeolites. 14 (1994) 402-410. doi:10.1016/01442449(94)90165-1.

[43] Y. Wang, Hybridation of layered oxides : from insertion to in situ synthesis, Université de Strasbourg, 2016.

[44] W. Fujita, K. Awaga, Reversible Structural Transformation and Drastic Magnetic Change in a Copper Hydroxides Intercalation Compound, J. Am. Chem. Soc. 119 (1997) 4563-4564. doi:10.1021/ja970239o. 